framum

Sociológico

\section{Forum Sociológico}

Série II

35 | 2019

Arte urbana: Contextos, tendências e desafios

\title{
Festivales de luz y eventos de luz en Portugal. Entre cultura y promoción turística del territorio.
}

Festivals of Light and Light Events in Portugal. Between Culture and Tourist Promotion of the Territory.

Festivais de luz e eventos de luz em Portugal. Entre cultura e promoção turística do território.

\section{Manuel Garcia-Ruiz}

\section{(Q) OpenEdition}

\section{Journals}

Edición electrónica

URL: https://journals.openedition.org/sociologico/8810

DOI: $10.4000 /$ sociologico.8810

ISSN: 2182-7427

\section{Editor}

CICS.NOVA - Centro Interdisciplinar de Ciências Sociais da Universidade Nova de Lisboa

\section{Edición impresa}

Paginación: 41-50

ISSN: 0872-8380

\section{Referencia electrónica}

Manuel Garcia-Ruiz, «Festivales de luz y eventos de luz en Portugal. Entre cultura y promoción

turística del territorio.», Forum Sociológico [En línea], 35 | 2019, Puesto en línea el 11 diciembre 2019 consultado el 29 marzo 2022. URL: http://journals.openedition.org/sociologico/8810 ; DOl: https:// doi.org/10.4000/sociologico.8810 


\title{
FESTIVALES DE LUZ Y EVENTOS DE LUZ EN PORTUGAL. ENTRE CULTURA Y PROMOCIÓN TURÍSTICA DEL TERRITORIO
}

\author{
FESTIVALS OF LIGHT AND LIGHT EVENTS IN PORTUGAL. BETWEEN CULTURE \\ AND TOURIST PROMOTION OF THE TERRITORY
}

\section{FESTIVAIS DE LUZ E EVENTOS DE LUZ EM PORTUGAL. ENTRE CULTURA E PROMOÇÃO TURÍSTICA DO TERRITÓRIO}

\author{
Manuel Garcia-Ruiz \\ Instituto Universitário de Lisboa (ISCTE-IUL), Escola de Sociologia e Políticas Públicas (ESPP), Centro de Investigação \\ e Estudos de Sociologia (CIES-IUL)
}

\begin{abstract}
Resumen
Los festivales de luz han sido adoptados a nivel internacional como herramientas para la democratización de las artes, para estimular las economías nocturnas, fomentar la citybrandificación y para superar la estacionalidad turística. Pero aún siguen siendo desconocidos en Portugal. El presente trabajo presenta los resultados exploratorios de un mapeo realizado a los centros de información turística con el objetivo de identificar la presencia de este tipo de eventos a nivel nacional. Nuestro análisis indica que los festivales de luz son confundidos de forma constante con otros tipos de eventos. Referimos aquí las confusiones más habituales, así como presentamos una tipificación de los eventos luminosos y sus características. Concluimos que el desarrollo e implantación de los festivales de luz en Portugal se ve comprometido por la saturación de eventos ya existentes, y por el desconocimiento de las potencialidades de este tipo de programas.
\end{abstract}

Palabras clave: festivales de luz, eventos de luz, festivalización, artes decorativas urbanas

\begin{abstract}
Festivals of light have been adopted internationally as tools for the democratization of the arts, to stimulate the night economy, foster city-branding, and to overcome seasonal tourism. However, these are not yet well known in Portugal. This article presents the exploratory results of a mapping carried out to tourist information centers, aiming to identify the presence of this type of event throughout the country. The analysis indicates that Light Festivals are constantly misunderstood with other types of events. In this paper we focus on the most common confusions, besides presenting a typification of light events and their characteristics. We conclude that the development and implementation of light festivals in Portugal are compromised by the saturation of existing events and the lack of knowledge of this type of program's potential.
\end{abstract}

Keywords: light festivals, light events, festivalization, urban decorative arts

\section{Resumo}

Os festivais de luz têm sido adotados internacionalmente como ferramentas para a democratização das artes, para estimular a economia noturna, fomentar a citybrandificação e para superar o turismo sazonal. Contudo, estes ainda não são bem conhecidos em Portugal. Este artigo apresenta os resultados exploratórios de um mapeamento realizado aos centros de informação turística, com o objetivo de identificar a presença deste tipo de evento em todo o país. A análise realizada indica que os Festivais de Luz são constantemente confundidos com outro tipo de eventos. Neste paper incidimos nas confusões mais comuns, além de apresentar uma tipificação dos eventos luminosos 
e suas características. Concluímos que o desenvolvimento e a implementação de festivais de luz em Portugal estão comprometidos pela saturação de eventos existentes e pelo desconhecimento do potencial deste tipo de programação.

Palavras-chave: festivais de luz, eventos de luz, festivalização, artes decorativas urbanas

\section{Introducción}

Los festivales, independientemente de su caracterización, tipo o contenido, han ganado progresivamente importancia al ser instrumentalizados como vehículos para la democratización de la cultura (Dubois, 1999; Wallach, 2006). Podríamos trazar esta tendencia desde el final de la Segunda Guerra Mundial, tras la que se comenzaron a crear programas de corte cultural y artístico (Autissier, 2008) más allá de las tradicionales festividades religiosas, rituales o folclóricas. La profesionalización de éstos nuevos eventos dio lugar a la creación de nuevas profesiones especializadas en gestión y planificación cultural (Tobelem, 2017), así como la revisión de las profesiones artísticas. Durante la segunda mitad del siglo pasado vendrían a cristalizarse, reinventarse y ajustarse a las necesidades emergentes de un universo en continua transformación.

Los eventos y festivales llegarían a alcanzar una gran popularidad en los años 1990, en la que podríamos identificar un crecimiento acelerado debido a su fácil replicación, consolidación en el mercado y popularización entre los responsables municipales, quienes los adoptaron como una forma rápida de estimular tanto el sector cultural, como el turístico, como el de promoción territorial (Bonet \& Schargorodsky, 2011; Quinn, 2005; Thomasson, 2015). La esperanza que subyace de esta articulación es la activación del turismo en épocas bajas -o fechas especificas- mediante acciones culturales, convirtiéndose la cultura en un catalizador para la visitación del municipio (Casado Cañeque, 2018; Cudny, 2016), al mismo tiempo que funciona para la creación de una imagen de marca (Herget, Petrů, \& Abrhám, 2015; Richards, 2017) al asociarse a un determinado tipo de evento o festival.

La multiplicidad de públicos, asociables a diferentes estilos de vida, facilita la proliferación y multiplicación de formatos, siendo esto una oportunidad para las autarquías para diferenciarse y atraer a un tipo especifico de visitantes-consumidores. La utilización de eventos para la consolidación de imagen de marca urbana, citybrandificación, es altamente utilizado aún hoy. Es común usar slogans que apelan a un determinado estilo de vida (asociado a un tipo de evento) para atraer o fidelizar a un público determinado. También podemos encontrar campañas de comunicación visual altamente apelativas y dirigida para un público diana muy bien definido a priori, que necesita ser nutrido de actividades de forma continuada.

Los eventos y festivales contribuyen, de forma evidente, para la entrada de los municipios en circuitos especializados, en las que compiten entre sí tanto para la conquista de públicos, como para la obtención de financiación; o en las que se asocian para el intercambio de contenidos, con la consecuente reducción de costes, tanto de producción como de realización (European Commission, 2019). Debemos pensar que las lógicas de la industria creativa y mercado global se encuentran bien entrañadas en este tipo de prácticas culturales o de entretenimiento.

Hoy en día, los festivales y eventos han sabido acercar diferentes formas culturales al gran público, así como que han conseguido elevar diversas prácticas, algunas anteriormente estigmatizadas, a contextos de exhibición eruditos (Heinich \& Shapiro, 2012), motivados o respondiendo a un apetito voraz y omnívoro de prácticas culturales por parte de unos públicos-consumidores en constante (auto) reinvención (Peterson, 1992; Peterson \& Kern, 1996). En este sentido, podríamos ver como diferentes formas de arte urbana han integrado, o alcanzado, el contexto de institucionalización y legitimización que las desliga de su origen popular en un proceso de artificación (Heinich, 2001; Shapiro, 2007). Por otro lado, y en contexto urbano, vemos como algunas prácticas artísticas transitan al espacio público, saliendo de un contexto tradicionalmente museístico, y transformando las calles en galerías de arte, aunque de forma efímera y fomentando las sociabilidades en contexto de festival.

La festivalización de la cultura (Bennett, Taylor, \& Woodward, 2014) describe perfectamente muchos de los procesos descritos hasta el momento, siempre teniendo en mente las diferentes relaciones entre espacio público y estilos de vida, usuarios de festivales y prácticas culturales, sin olvidar la función del espacio público como lugar de encuentro.

Como indicábamos anteriormente, son muchos los formatos y tipos de festivales disponibles en la actualidad, especialmente después de la intensificación y diversificación experimentada en las últimas décadas. Los festivales de luz son un tipo de programación muy heterogénea que se desarrollan en el espacio público con una ventana de tiempo variable, siendo habitual, que sean unos pocos días. Estos festivales han sido adoptados de forma masiva por las cámaras municipales a escala internacional 
en los últimos años, bajo el prisma de completar las agendas de entretenimiento y cultura local ya que se desarrollan en horario nocturno (Papadaki, 2015; Sloan, 2015). Igualmente, estos eventos han demostrado su valor para atraer grandes volúmenes de usuarios indiferenciados, reactivar o reforzar la economía nocturna y el turismo cultural (Giordano, 2017; Kadri \& Khomsi, 2017; Rius Ulldemolins, 2014). Sin embargo, no son conocidos por igual en todo el territorio nacional portugués, siendo comúnmente confundidos con eventos tradicionales, decoraciones festivas o celebraciones ya presentes heredadas del pasado.

En este trabajo, presentamos los resultados exploratorios de un mapeamento nacional que pretende identificar los festivales de luz existentes en Portugal, al mismo tiempo que identificar con qué otro tipo de evento son confundidos de forma general. Su identificación, esperamos, pueda contribuir en la planificación y gestión más eficaz de los recursos, así como en la consolidación de los mismos.

\section{Metodologia}

Con objeto de poder localizar e identificar los diferentes eventos y festivales de luz presentes en Portugal, procedimos a contactar a todos los centros de información turística, o en caso de un municipio no contar con este tipo de servicio, con los responsables de turismo, cultura o comunicación. Optamos por contar con este público como informante debido a su alto grado de conocimiento sobre las actividades que se realizan en su municipio. Es de esperar de estos profesionales que sepan y que estén actualizados sobre todas las acciones culturales y turísticas que se desarrollan, o vayan a desarrollarse, con fin de promocionarlas y darlas a conocer (muestreo de expertos).

Contamos con el $78 \%$ de participación ( $n=241$; $\mathrm{N}=308$ ). El mapeo consistió en un cuestionario auto-asistido on-line de preguntas abiertas. Videos explicativos y referencias a eventos o festivales de luz de corte internacional fueron presentados para disipar cualquier duda. Estuvo disponible durante tres meses (de enero a marzo de 2017) bajo invitación vía email, garantizando el anonimato en la participación.

Aquí presentamos las confusiones más recurrentes en las respuestas obtenidas con respecto a los tres contextos de exhibición de arte luz urbana, proponiendo una definición y clarificación inicial.

\section{Festivales de luz en Portugal}

Los festivales de luz han crecido a ritmo acelerado en las últimas dos décadas, permaneciendo como referencia histórica y como modelo para aprovechar este tipo de programación cultural, la
Fête des Lumières en Lyon (Francia). Este evento se destaca por la naturaleza espectacular de sus intervenciones artísticas, su compromiso con la innovación, su calidad curatorial, así como su capacidad de aprovechar una importante oportunidad en términos de gestión cultural: transformar una tradición profundamente arraigada, en un producto cultural de masas. Obviamente, su continuidad y éxito están vinculados a una estructura organizacional bien definida y a una colaboración importante con inversores externos y autoridades locales. Este evento fue establecido como un destino turístico y como un elemento cultural de gran valor en el área, así como en el contexto internacional.

La Fête de Lumière en tanto que "festival de luz" remonta a 1999, si bien como "evento de luz" es trazable a 1988, momento en el que se inician experimentaciones con la iluminación arquitectónica de determinados edificios emblemáticos de la ciudad (Roda Fernandes, 2011). Pero, como decíamos, este producto cultural que atrae a más de 1.8 millones de espectadores, locales e internacionales, en apenas cuatro noches (Direction des Evénements et de I'Animation, 2018), tiene como base una tradición que remonta a 1852 en la que las gentes de la ciudad decidieron colocar velas en las ventanas, como muestra de solidaridad y unión ciudadana ante las inclemencias meteorológicas y los atrasos que éstas causaban para la inauguración de una estatua conmemorativa a la virgen patrona. Esta tradición evolucionó en un desfile con velas en la ciudad el día 8 de diciembre de cada año, y hoy es la antesala para el inicio del festival.

En Portugal, el primer "festival de (arte) luz" surgió de la mano de una asociación cultural aunando arte y urbanismo táctico. La Associação Extra Muros (AEM), ahora ya extinta, diseñó el primer programa cultural sobre arte luz con un formato diferente a los hoy populares festivales de luz. Para los promotores hacía mayor sentido crear una Bienal de la $L u z$, incluyendo conferencias, workshops, y otras actividades de forma paralela durante el periodo de realización. Este programa fue Ilamado Luzboa, y desgraciadamente sólo contó con dos ediciones. El origen de Luzboa se encuentra en un evento anterior: Lisboa, Capital do Nada, el cual tuvo lugar en el barrio de Marvila con la participación de los moradores y una gran cantidad de artistas profesionales y debutantes en el año 2001.

Lisboa, Capital do Nada generó gran controversia por su título, pues en un primer momento podía ser entendido como una crítica social (teniendo en cuenta que se realizaba en un barrio con alta inmigración irregular), pero pronto contó con los apoyos institucionales necesarios para su compleción al descartar esta idea y entender que era una mera metáfora referente a la posibilidad de que todo podía suceder. El impacto de este evento fue 
Figura $1 \triangleright$ Banner con el recorrido del festival en 2006. Indicando las diferentes instalaciones en el espacio urbano lisboeta
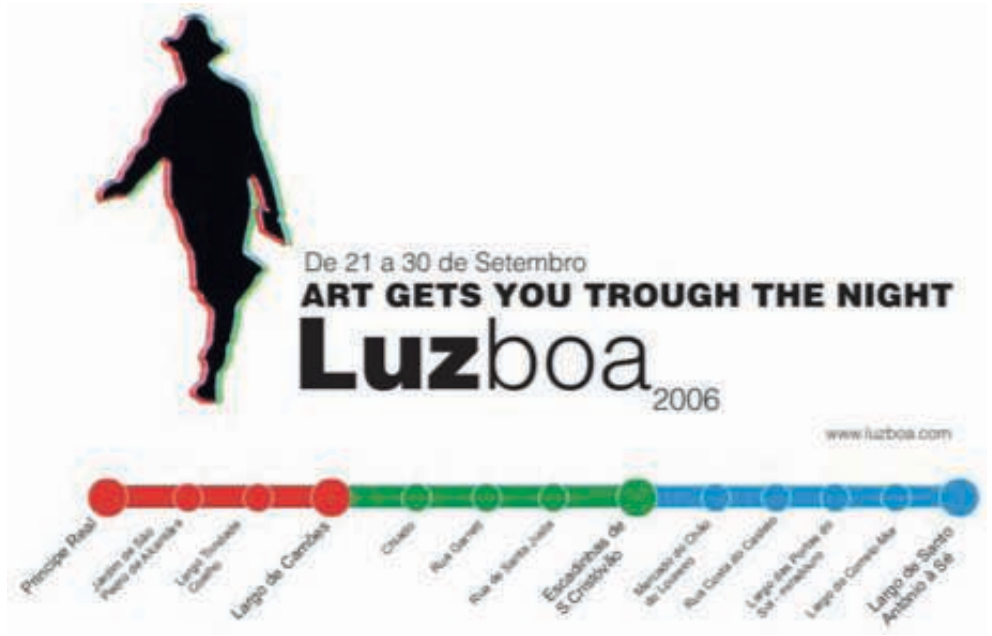

Fuente: Arquivo.

mayúsculo, Ilamando la atención de otras instituciones que vendrían a colaborar con la AEM, entre ellas el Instituto de la Cultura Francesa en Portugal. De esta colaboración surgió el Luzboa 2004. La primera edición dispuso de un presupuesto adecuado para la realización de un evento de larga envergadura, articulado en dos líneas principales: por un lado, la ocupación del espacio público urbano con diferentes piezas de arte luz con intención de acercar y familiarizar este tipo de arte al gran público; y por otra, la realización de subeventos formativos, académicos y de investigación. Los resultados en términos de visitación fueron importantes, tal como apunta Roda Fernandes (2011) con unos 250000 visitantes. Importante, no sólo por el número elevado, sino también por ser visitantes "vírgenes" dispuestos a explorar algo nuevo. Esta primera edición sentó las bases para la segunda en 2006, la cual contó con casi el doble de visitantes (Roda Fernandes, 2011), pero con un presupuesto más reducido, debido a reajustes presupuestales por parte de las instituciones participantes. La segunda edición, con mayor perspectiva curatorial concentraba las piezas en tres itinerarios designados como Red, Green, Blue (RGB), jugando con la idea de los colores primarios de la luz. Cada color representaba una parte del recorrido diseñado. Las farolas e iluminación pública fueron alteradas con filtros que casaban con estos colores, permitiendo ubicarse fácilmente en el mapa, o programar la visita de mejor forma.

Artistas, curadores, científicos sociales, y otras personalidades relacionadas con la luz, el arte luz y la iluminación se dieron cita durante las dos ediciones del festival. Estos encuentros marcarían la carrera de varias personas, tanto nacionalmente como internacionalmente. En términos nacionales, surgirían de esta cantera los responsables del Festival Aura (Sin- tra, 2015-); parte del equipo de producción del Festival Luza, inicialmente en Loulé (2017-2018), actualmente en Faro (2019); y marcaría de forma importante la trayectoria y nacimiento del Festival Lumina, inicialmente en Sintra (2011), posteriormente en Cascais (2013-2018). Por otro lado, marcaría la trayectoria profesional de sus organizadores, Teresa Alves como geógrafa de la noche; Mario Caeiro, como curador de diferentes festivales y eventos de luz; y Samuel Roda Fernandes como responsable del Festival Aura y especialista en arquitectura e iluminación.

Otros eventos surgieran de esta bienal, como el breve festival Óbidos Luz organizado por Caeiro y Cabau en 2013, o el Vicente en la Travessa da Ermida en Belén, aún en andamiento desde 2011. Sin embargo, pocos de estos festivales de luz tienen una conexión fuerte con tradiciones o ritos preexistentes. Esta situación, al contrario del caso de Lyon o de otros festivales que se unen -o derivan- de tradiciones, presupone exponer a los locales a un nuevo formato cultural en el que quizá no se identifiquen y que pueden llegar a reconocer como extraño; o bien, que no sean capaces de diferenciarlo, por ejemplo, de la decoración navideña de las calles.

\section{No todo lo que brilla es un festival de luz}

La luz eléctrica revolucionó completamente la historia contemporánea, creando la posibilidad de alargar las jornadas de trabajo, disminuyendo los peligros de incendio e intoxicación de los empleados, así como que facilitó la navegación nocturna en el espacio público de forma más eficaz que los sistemas de gas (Cordeiro, 2005). No tardaron en llegar formas, más o menos creativas, que supieron utilizar estas tecnologías para fines culturales o artísticos, como podríamos encontrar en la obra de Laszlo Moholy-Nagy, fotógrafo y pionero del arte luz, y miembro de la Bauhaus, quien trabajó con neón y otras bombillas a principios del siglo pasado. Sin embargo, no sería hasta la década de los 60 del siglo pasado, en el que aparecería un movimiento artístico, asociado al op-art, al minimalismo y a la abstracción geométrica, que sentaría las bases del arte luz; hablamos del movimiento Light and Space. Este grupo, aún con miembros en activo, viene influyendo de forma notoria los trabajos que podemos encontrar en los diferentes eventos donde la luz es usada como medio. No pretendemos decir que los trabajos que encon- 
tramos en los diferentes eventos, que explicaremos a continuación, pertenezcan a este movimiento, sino que fueron -de alguna forma- influenciados por él. Rara vez (aunque no imposible) encontraremos en este tipo de eventos trabajos de James Turrell, Olaf Eliassor, o Caster Brindle, por citar algunos de los miembros aún activos hoy y que continúan a realizar exposiciones a nivel internacional.

Obras y artistas influenciados por esta corriente artística, así como otros profesionales creativos que trabajan la luz, integran los festivales de luz, los cuales hacen de esta heterogeneidad, cada vez más compleja, la llave de un campo en construcción (Bourdieu, 2015). Sin embargo, muchas veces se cuestiona su artificidad (Shapiro, 2007), puesto que los festivales de luz incluyen todo tipo de proyectos en los que la componente lumínica sea estéticamente agradable para el ojo de un visitante no especializado, aunando prácticas y expresiones de campos no completamente artísticos. Este punto es muy importante, ya que hablamos de festivales y eventos institucionalizados en los que el no-arte y el arte conviven y comparten programa, dándose procesos de contaminación simbólica entre ambos. Esta coexistencia podría justificar, sin duda, los resultados obtenidos.

Cabe destacar que las obras que encontramos en estos eventos, a diferencia del grafiti, del street art, u otras formas de arte urbana, no nacen en la calle, sino que son llevados a la calle -normalmentecomo resultado de un proceso de selección por expertos, un contrato de servicios, y de un maridaje previo obra-lugar, todo dentro de una lógica capitalista de consumo de obras o pseudo-obras de arte. La creación de un programa es en proceso realizado de forma colectiva y de cooperación por parte de curadores, directores, artistas y otros individuos que componen un complejo y variable mapa de actores (Becker, Menger, \& Bouniort, 2010). Por lo tanto, hablamos de contextos de exhibición institucional de prácticas y expresiones artísticas que ocupan el espacio urbano de forma efímera y programada, lo que podría -a priori- justificar su consideración como arte pública, especialmente cuando estos eventos responden a políticas desarrolladas por las autarquías locales.

Por otro lado, estos contextos de exhibición que comentamos compiten con otras prácticas de ocupación del espacio urbano, normalmente con un enraizamiento cultural y festivo, respondiendo a prácticas rituales, religiosas, conmemorativas, etc. Estas prácticas ya existentes hacen parte de la cultural del local y su performatividad puede incluir elementos lumínicos, más o menos elaborados. Es importante destacar que a diferencia de los elementos arriba indicados, estos no cuentan con un equipo de curadores especializados, ni profesionales, sino que en la mayor parte de las veces son orga- nizadores sin formación especializada o por grupos relativamente amateurs, agrupados mediante la forma de asociaciones culturales o festivas, y que se ocupan de su proyección, su puesta en escena y su realización de forma cooperativa y conjunta. De la misma forma, estas prácticas normalmente no incluyen expresiones artísticas o performativas de fuera del municipio, quedando circunscritas a representaciones y ejercicios de reproducción del folklore local y de la cultura popular, relativamente sensibles y porosos de la cultura mainstream del momento. Durante la investigación fueron identificados 15 tipos de eventos, con mayor o menor nivel de confusión con los eventos curatoriados.

Presentamos a continuación los tres contextos de exhibición controlada y programada de proyectos de luz identificados, sustancialmente diferentes entre sí como para poder hacer distinción. La diferencia entre estos, que perfectamente podrían incluirse dentro de las industrias culturales y creativas, radica en su tiempo de exposición, su programación interna, así como su autonomía.

\section{Los eventos de luz}

Estos eventos son entendidos como contextos de exhibición de piezas y pseudo-piezas de arte donde la luz es usada como medio. Son de corta duración, aunque puedan ser repetidos en el mismo día varias veces, o en días consecutivos. Destaca el hecho de ser una obra única, en un lugar único, y no tener relación con otras piezas; no integran una programación mayor. Destacan por su uso habitual reciente los videomappings, los cuales han ganado gran notoriedad por su capacidad de reactivar el parque patrimonial urbano sin ser invasivos. Otras formas de evento de luz, de carácter más tradicional, podrían incluir: fuegos pirotécnicos, quema de objetos (barcos, troncos, figuras de cartón-piedra...), etc. Estas formas artísticas deben ser reconocidas como independientes, no deben hacer parte de ningún otro programa, siendo por sí mismos la atracción principal.

Si bien deben ser autónomas y tener valor por sí mismas, parece que la confusión es fácil y su correlación con las fiestas patronales es recurrente. Las fiestas patronales no dejan de ser configuraciones festivo-culturales que reúnen diferentes formas de expresión con unos objetivos bien definidos: entretener, fomentar el convivio cívico, transferencia de valores... pero no son el tipo de programa cultural descrito al inicio de esta sección. De la misma forma, y por su componente artístico o cultural, son confundidos con eventos de fomento de la cultura, tales como exposiciones o proyecciones cinematográficas, sin embargo, éstas responden a otro tipo de acciones o programas -muchas veces derivados de otro tipo de políticas públicas. Podríamos citar algunos 
trabajos explicativos tales como los videomapping en el Terreiro do Paço, en Lisboa, por ejemplo: $O$ Novo Palácio do Nicolau (Figura 2), producido por el atelier Grandpa's Lab para la EGEAC y la CML en 2016; o Lisbon Under the Stars (Figura 3), producido por OCUBO y desarrollado en la Ruinas del Convento do Carmo en la capital portuguesa.
El periodo natalicio causa especial confusión, ya que incluye la iluminación de las calles, una práctica decorativa bien arraigada internacionalmente. En Portugal no es habitual que los propios individuos decoren sus hogares con luces como en otros países (Edensor \& Millington, 2009), siendo las cámaras municipales las encargadas de asignar la decoración

Figura $2 \gg$ Izquierda, cartel del video mapping O Novo Palácio do Nicolau. Centro y derecha, imágenes de las proyecciones en la facha del arco de la victoria en la Plaza de Comercio, Lisboa
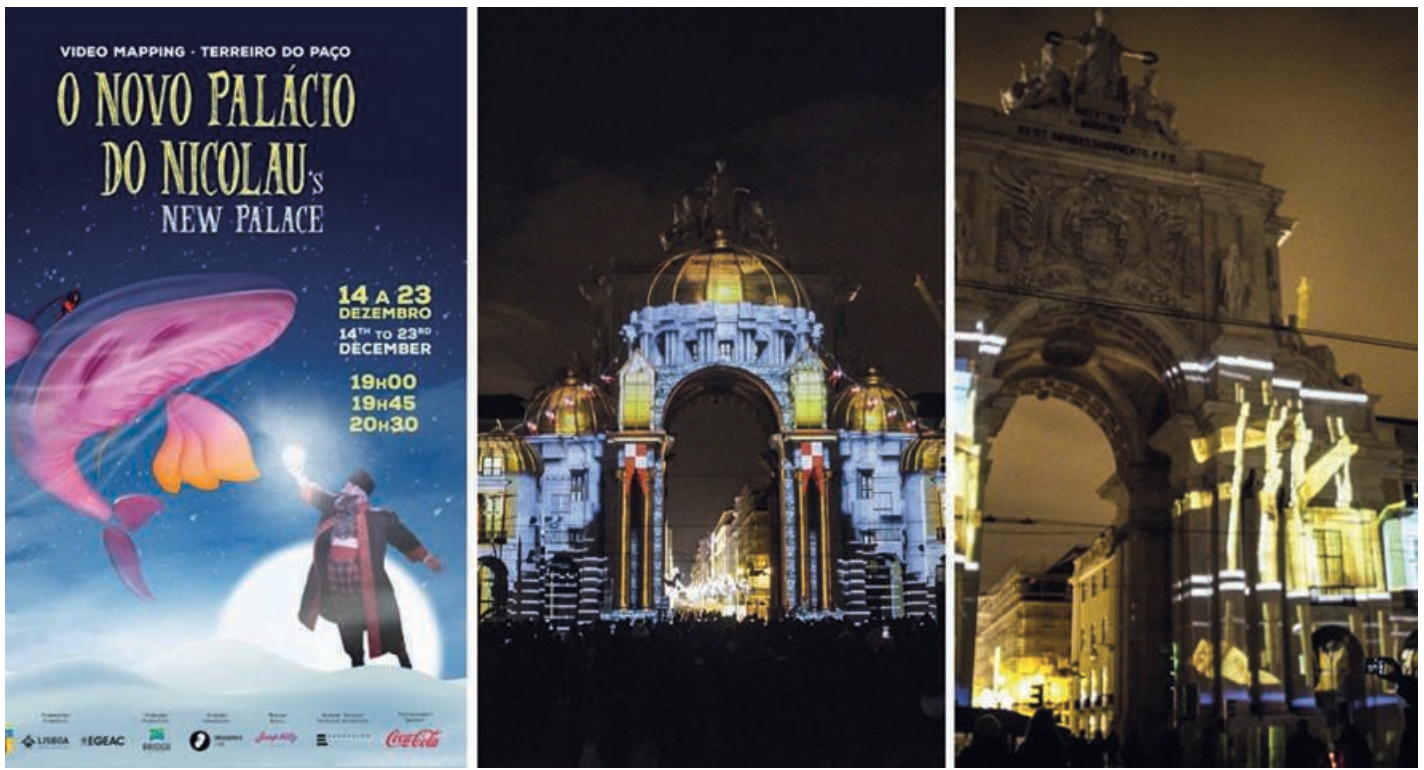

Fuente: Fotografías de GrandPa's Lab disponibles en www.grandpaslab.pt/portafolio (30 mayo de 2019).

Figura $3 \triangleright$ Izquierda cartel del espectáculo inmersivo Lisbon Under Srtars, Ruinas do Carmo, Lisboa. Centro y derecha, imágenes del espectáculo en las ruinas
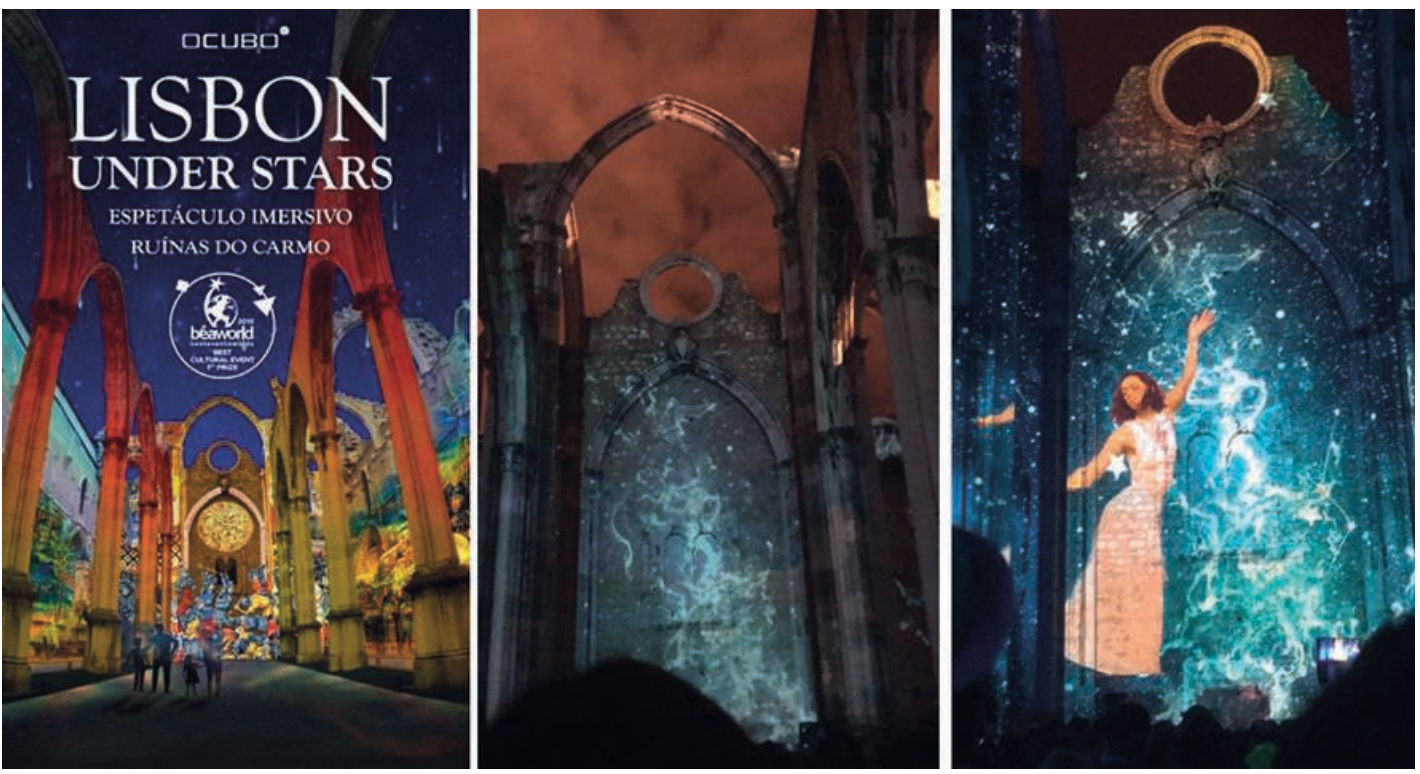

Fuente: Archivo, y fotografías del autor (3 mayo 2017). 
a empresas terciarias, que por lo general no invierten en innovación o en creatividad. Otras veces, las municipalidades poseen equipo decorativo para la noche, siendo las mismas estructuras repetidas anualmente, siguiendo planos de rotación entre los barrios para minimizar la continuación-memoria visual año tras año. Otros elementos que causan confusión con los eventos de luz suelen ser las recreaciones de nacimientos, las cuales se integran en las celebraciones navideñas y no son independientes per se. La tradición de algunas regiones con los "madeiros de natal" se suma al entendimiento de estos como elementos de luz, pero siempre quedan circunscritos a la celebración navideña.

El paso de año es uno de los eventos en el calendario portugués donde la pirotécnica destaca por si misma, siendo usada como acto conmemorativo o festivo a la media noche, para dar entrada al año nuevo; sin embargo, es usada como complemento y rara vez se le da valor artístico. Por otro lado, sigue siendo usada de forma regular en eventos laicos, celebraciones de la cosecha, etc. Su uso tradicional y su relativo bajo coste hacen de la pirotécnica una de las formas preferidas para iniciar o concluir celebraciones locales.

Por último, es importante comentar que 56 municipios indicaron que no cuentan con ningún tipo de evento de luz único. Esto significa que no cuentan con elementos independientes, quedando siempre circunscritas las obras de arte luz con otro tipo de programación mayor.

\section{Eventos insertos en otra programación}

La creación de eventos en el espacio público implica grandes costes, derivados del gran despliegue humano, artístico y de medios que son necesarios para la realización de éstos. Es por este motivo que en muchos casos los festivales de luz, así como los eventos de luz, son integrados en otros tipos de programas, intentando, de esta forma, abaratar los costes derivados de su celebración. Encontramos ejemplos de este tipo de decisiones de producción en muy diferentes contextos como podría ser el caso del festival de luz Llum, en Barcelona, que ocurre durante las fiestas patronales en honor de Santa Eulalia; o el caso del Festival Illuminart, inserto en el programa cultural Montréal en Lumière en Montreal.

Como apuntan Hunyadi, Inkei, and Szabó (2008) todos los festivales sufren de perdidas directas o indirectas, pero benefician a las economías locales en gran medida (aunque sea difícil definir cómo), justificando su realización y haciendo su subvención algo necesario. La financiación por vía de estos eventos, a veces, es la única forma de conseguir que un festival de luz o que una determinada pieza de arte-luz llegue al gran público. Por otro lado, inserir este tipo de eventos dentro de otra progra- mación ayuda en la comunicación y divulgación de la actividad, garantizando una mayor visualización en términos mediáticos que puede llegar a beneficiar en términos de visitación.

La inclusión de obras o trabajos de luz en las fiestas portuguesas es habitual, sin embargo, no encontramos ninguna en que la que gocen de la independencia necesaria para ser considerados como eventos o festivales autónomos, aunque formen parte de otro programa cultural. Los informadores de turismo apuntan, no obstante, que en 26 localidades podemos encontrar trabajos de luz en fiestas patronales, muchas veces relacionados con fuegos de artificio y videomapping. Por otro lado, y como constante, aparecen las celebraciones de año nuevo, caracterizadas por fuegos de artificio. Como en el caso anterior vemos que las iluminaciones públicas son consideradas como obras de arte insertas en otra programación, la navideña; sin embargo, estas estructuras luminosas no cumplen el principio artístico en su creación, siendo simples piezas de ornamento urbano.

Es de esperar que este contexto de exhibición de piezas fuera el más confuso, pues dentro de celebraciones religiosas, patronales, o de otra índole se inserta un festival o evento de luz. Las fronteras en este tipo de contexto de exhibición se hacen muy difíciles de identificar, especialmente cuanto más ricas en formas de expresión luminosa pueda ser el programa madre, mayor sea la difusión mediática y menos autónoma sea el equipo de organización, el evento, y su estética. La ruptura con el contexto de presentación inicial, muchas veces, no llega a realizarse, pues estructuralmente los actores envueltos no cuentan con la libertad, ni recursos, ni capacidades instrumental o técnicas.

\section{Los festivales de luz}

Los festivales de luz son programaciones culturales de duración variable que integran diferentes registros artísticos, teniendo éstos en común el uso de la luz como medio. Estos festivales pueden durar desde dos o tres días, en sus versiones más cortas, a varios meses, en sus versiones extendidas. Igualmente, tienen como característica ocupar diferentes espacios urbanos, tanto públicos, como privados y ser de acceso fácil y gratuito para el visitante. Para su visitación, se construyen itinerarios que conectan los diferentes lugares que acogen las piezas artísticas, dirigiendo la foule para maximizar el flujo de visitantes en la ciudad.

Los festivales de luz, en líneas generales, responden a un tema anual elegido por los curadores o directores artísticos, muchas veces influenciados por motivaciones económicas (relaciones con los sponsors); oportunísticas (eventos anuales relacionados con el lugar a ser realizado, años especiales 
Figura $4 \triangleright$ Izquierda, luces ornamentales en la Avenida da Liberdade, Lisboa. Centro, luces ornamentales en la Av. Guerra Junqueiro. (30 noviembre 2016). Derecha, instalación de iluminación natalicia próxima a Plaza de Londres, Lisboa (19 octubre 2016)
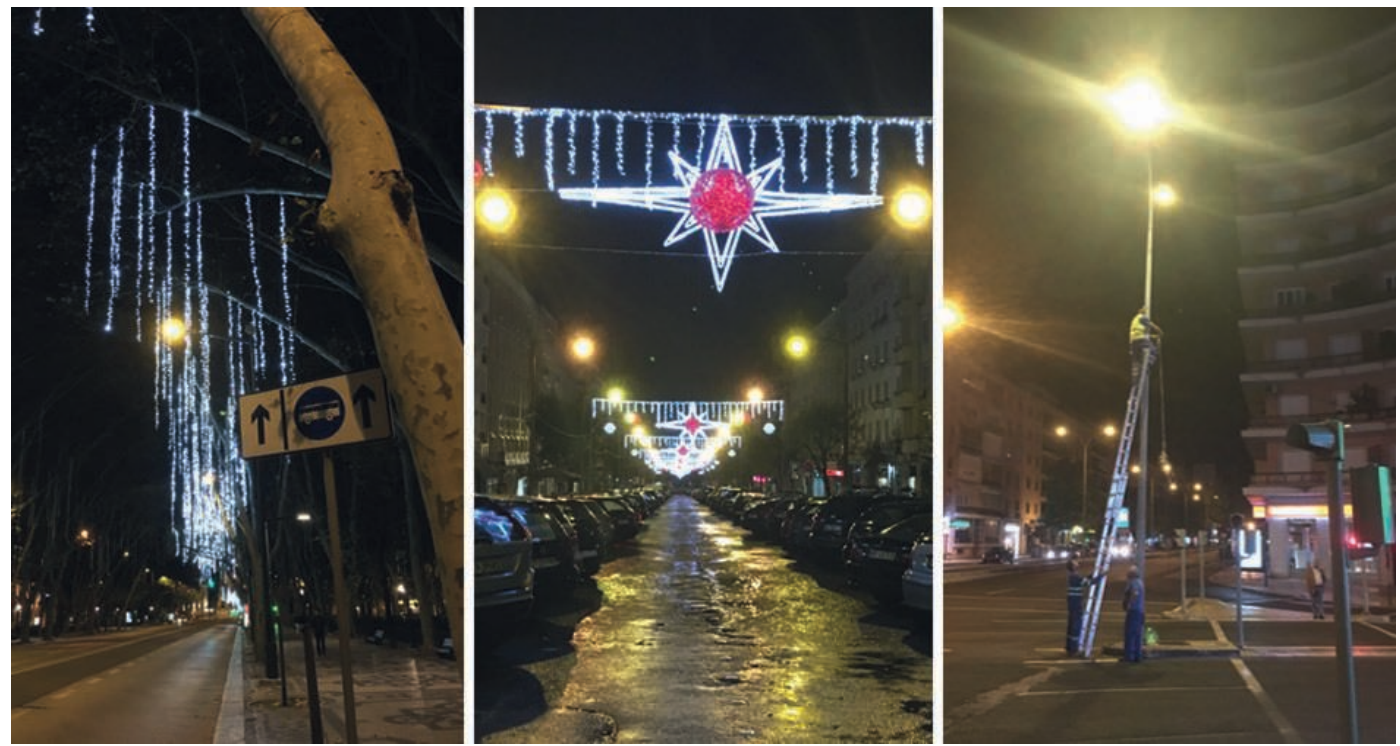

Fuente: Archivo, y fotografías del autor.

nombrados por la UNESCO...); históricas o celebrativas (aniversario del festival), etc. Esta temática ayuda en la elección de piezas y en la composición del programa, intentando crear un diálogo entre las diferentes obras que conformarán el cartel final y los lugares donde serán instaladas.

En Portugal y en 2017, encontrábamos dos grandes festivales de luz. Por un lado, el festival Lumina Cascais con una visitación estimada de 400000 personas anualmente, con unas 25 piezas anuales y una duración de cuatro noches. Lumina Cascais estaba sedeado en Cascais y organizado por el atelier OCUBO -quizá la empresa de creación multimedia más relevante en territorio nacional. Por otro lado, Aura Festival con una visitación estimada de 70000 personas anualmente, con unas 15 piezas anuales y una duración de cuatro noches. Aura está sedeado en Sintra y está organizado por la Asociación Cultural Creaatividade Cosmica. Ambos festivales fueron identificados como festivales de luz por los informadores de turismo de las respectivas ciudades, sumándoseles sólo otro festival: Festival de Luz e do Videomapping de Lousada. Este último, organizado por la Camara Municipal de Lousada en colaboración con escuelas y universidades de la región, destaca sobre los otros dos por aproximarse a un modelo de creación colaborativa, amateurística, al integrar trabajos no profesionales realizados por personas locales y por buscar, de esta forma, la creación de un sentimiento de orgullo local, fomentar la creatividad del municipio y favorecer una sensación de pertenencia.

Es interesante ver que 223 informadores de turismo reportaron que su municipio no tenía ningún tipo de festival, que respondiera a la descripción de "festival de luz". Esta situación ilustra la baja penetración de este tipo de programación dentro del escenario cultural portugués, así como su concentración -hasta el momento- en municipios cercanos a Lisboa. Una posible explicación a esta situación es la capacidad de succionar público de la capital, en un desplazamiento cercano y realizable con trasporte público o su propio vehículo (aproximadamente 30 $\mathrm{km}$ en ambos casos); siendo entendido este viaje como un acto de ocio alternativo y de ruptura de la rutina.

Llama la atención el hecho de que algunos informadores los confundieran con las fiestas patronales. El uso generalizado de video-mapping puede justificar esta confusión, así como el uso tradicional de fuegos de artificio. Las otras categorías se ajustan al mismo patrón ya explicado en los puntos anteriores.

\section{Nuevos festivales}

Después de la conclusión de este mapeamento, apareció en Loulé un nuevo festival de luz: LUZA, Festival de Luz del Algarve. Este nuevo festival de luz nació bajo el programa Algarve 365 y la tutela de la Cámara Municipal de Loulé. Consistente en un programa de arte luz en el espacio público, y en algunos edificios de propiedad municipal, se consolidó en los meses de baja visitación turística con la intención de reactivar el municipio en baja estación. En su primera edición (2017) y según las fuentes oficiales, aproximadamente 30000 personas visitaron el festival. Compuesto por 15 piezas de 
arte-luz y tres noches. Cabe destacar que cumple con los requisitos de la convocatoria de subvención, aunando arte y cultura, promoción territorial a nivel regional e innovación para la zona.

\section{Artistas de luz}

Por otro lado, muchas veces los artistas optan por trabajar fuera del mercado artístico y colaboran con otras estructuras tales como conciertos, promotoras comerciales, compañías de relaciones públicas o comunicación. Por este motivo, muchas veces podemos encontrar las mismas tecnologías, las mismas obras, los mismos nombres en contextos diferentes. Frecuentemente encontramos la colaboración de muchos artistas, que participan en festivales de luz, en conciertos de música electrónica, como iluminadores en teatros, como cineastas, etc. Esta participación múltiple en eventos de diferente índole por parte del artista hace difícil, muchas veces, la definición de un evento, y puede difuminar la categoría de éste en términos artísticos. Debemos mantener en mente que cuando un artista trabaja en un circuito intencionalmente no-artístico está actuando en tanto que trabajador especializado y no como artista, desproveyendo el objeto creado de su consistencia artística.

Debemos destacar la mención a un festival musical internacionalmente conocido: Boom Festival, el cual reúne en su programación excelentes trabajos de diseño de luz, arquitectura de luz, stage lightning y performance de luz. Sin embargo, como comentábamos, los artistas o diseñadores que participan no entran en su calidad de artistas sino como profesionales de la iluminación. Debemos recordar que estas producciones no son consideradas como independientes o que no cuentan con un programa que les otorgue la importancia, atractivo o interés artístico por si propias, siendo relevadas a trabajo de iluminación efímero, como cualquier otro escenario para conciertos.

\section{Reflexiones a modo final}

Los eventos de luz en Portugal están a ser subestimados, no siendo completamente explorados ni entendidos, muchas veces por considerar que ya se posee un evento de similares características. Estos eventos "semejantes", herederos de la tradición o fruto de una reproducción programática reiterada, sumado a este desentendimiento de las artes ( $y$ en especial de las artes luz), hacen que los formatos curatoriados, diseñados con objetivos claros de turistificación y atracción de turismo cultural, reactivación de la economía nocturna y diseño de marca urbano, no entren en juego.

No hablamos de sustituir la tradición con nuevos formatos, pero tal vez de reimaginar el espacio público y establecer una estrategia a mayor escala para poder competir en términos artísticos con otros municipios, integrando redes internacionales de turismo cultural.

Estos festivales, eventos de luz y eventos integrados, tienen la posibilidad de atraer un público diferente, motivado y con gusto por las artes. Su breve duración los hace excepcionales para reactivar un municipio en época baja y aumentar su revenue, al mismo tiempo que se convierten en fantásticas ventanas abiertas para que los locales empiecen a relacionarse con las artes, aprendan nuevas formas de expresión o simplemente se deleiten con la estética de las obras. En cualquier caso, pueden convertirse en herramientas para aumentar los niveles de satisfacción de un municipio, despertar un cierto urban awareness y un sentimiento de pertenencia como refería Bennett (2014).

Como decíamos, el mercado de estos eventos se encuentra en una fase muy inmadura y esperamos que, en los próximos años, los profesionales del turismo y los profesionales de la programación cultural adquieran nuevas competencias y sensibilidades con las artes, incorporando las artes luz como una formula de éxito -siempre que programado- para sus respectivos municipios, aprovechando las potencialidades para la citibrandización y festivalización de este tipo de programas.

\section{Agradecimientos}

Este trabajo fue posible gracias al financiamiento de la Fundação para a Ciencia e a Tecnologia (FCT) SFRH/BD/121842/2016

\section{Referencias}

Alves, T. (2004). Geografias da Noite . Fazer Geografia Através da Luz. Paper presented at the V Congresso da Geografia Portuguesa. Territórios e Protagonistas, Universidade do Minho.

Alves, T. (2007). Art, Light and Landscape New Agendas for Urban Development. European Planning Studies, 15(9), 1247-1260. doi: $10.1080 / 09654310701529243$

Autissier, A. M. (2008). L'Europe des festivals: de Zagreb à Edimbourg, points de vue croisés: Attribut.

Becker, H. S., Menger, P.-M., \& Bouniort, J. (2010). Les mondes de l'art présentation de Pierre-Michel Menger traduit de I'anglais par Jeanne Bouniort. Paris: Flammarion.

Bennett, A., Taylor, J., \& Woodward, I. (2014). Festivalisation of Culture.

Bonet, L., \& Schargorodsky, H. (2011). La gestión de festivales escénicos: conceptos, miradas y debates. (Vol. 6). Barcelona: Universidad de Barcelona.

Bourdieu, P. (2015). Les règles de l'art genèse et structure du champ littéraire (Éd. revue et corrigée ed.). Paris: Éditions du Seuil. 
Caeiro, M. (2004). Luzboa. Lisboa: Extra Muros.

Caeiro, M., \& Pottier, M. (Eds.). (2004). Luzboa: a arte da luz em Lisboa. Monte da Caparica: Extra Muros-Associação Cultural para a Cidade.

Caeiro, M. J. (2002). Lisboa capital do nada. Lisboa: Extra Muros.

Campos, R. (2010). Porque pintamos a cidade? [S.I.]: Fim de Século.

Casado Cañeque, F. (2018). Festivales urbanos para reconstruir las ciudades.

Cordeiro, B. (2005). A iluminação:para lá da electricidade. In N. L. Madureira (Ed.), A História da Energia. Lisboa: Livros Horizonte.

Cudny, W. (2016). Festivalisation of Urban Spaces : Factors, Processes and Effects. Switzerland: Springer International Publishing.

Direction des Evénements et de I'Animation, V. d. L. (2018). Fête des Lumières Lyon. Retrieved from http://www.fetedeslumieres.lyon.fr/

Dubois, V. (1999). La politique culturelle genèse d'une catégorie d'intervention publique. Paris: Belin.

Edensor, T., \& Millington, S. (2009). Illuminations, Class Identities and the Contested Landscapes of Christmas. Sociology, 43(1), 103-121. doi: $10.1177 / 0038038508099100$

European Commission. (2019). Creative Europe. Monitoring Report. Retrieved from Luxembourg: https:// ec.europa.eu/programmes/creative-europe/sites/ creative-europe/files/library/creative-europemonitoring-report-2018.pdf

Giordano, E. (2017). Outdoor lighting design as a tool for tourist development: the case of Valladolid. European Planning Studies, 26(1), 55-74. doi:10 $.1080 / 09654313.2017 .1368457$

Heinich, N. (2001). Art contemporain, dérision et sociologie. Hermês, 29, 121-130.

Heinich, N., \& Shapiro, R. (2012). De l'Artification. Enquête sur le passage à l'art. Paris: Editions EHESS.

Herget, J., Petrů, Z., \& Abrhám, J. (2015). City branding and its economic impacts on tourism. Economics and Sociology, 8(1), 119-126. doi:10.14254/2071789X.2015/8-1/9

Hunyadi, Z., Inkei, P., \& Szabó, J. Z. (2008). Les festivals Hongrois à la Loupe. In A. M. Autissier (Ed.), L'Europe des Festivals. De Zagreb à Édinbourg, points de vue croisés. Saint-Denis: Éditions de l'Attribut.
Kadri, B., \& Khomsi, R. M. (2017). La metrópoli cultural y turística: ¿una nueva cara de la globalización? methaodos.revista de ciencias sociales, 5(1). doi: $10.17502 / m . r c s . v 5 i 1.154$

Papadaki, E. (2015). Curating Lights and Shadows, or the Remapping of the Lived Experience of Space. The Senses and Society, 10(2), 217-236. doi: 10.1080/17458927.2015.1042247

Peterson, R. A. (1992). Understanding audience segmentation: From elite and mass to omnivore and univore. Poetics, 21, 243-258.

Peterson, R. A., \& Kern, R. M. (1996). Changing Highbrow Taste: From Snob to Omnivore. American Sociological Review, 61(5), 900-907. doi:10.2307/2096460

Quinn, B. (2005). Arts Festivals and the City. Urban Studies, 42(5-6), 927-943. doi: 10.1080/ 100420980500107250

Richards, G. (2017). From place branding to placemaking: the role of events. International Journal of Event and Festival Management, 8(1), 8-23. doi:10.1108/IJEFM-09-2016-0063

Rius Ulldemolins, J. (2014). Culture and authenticity in urban regeneration processes: Place branding in central Barcelona. Urban Studies, 51(14), 30263045. doi: $10.1177 / 0042098013515762$

Roda Fernandes, S. (2011). Construção e reabilitação dos espaços públicos através da arte contemporânea - os contributos da Extra]Muros[ - Associação Cultural para a Cidade, na programação cultural e social do espaço público entre 2001 e 2007. (PhD Architecture). Escuela Técnica Superior de Arquitectura de Sevilla, Sevilla.

Shapiro, R. (2007). Que é artification? Sociedade e Estado, 22(1), 135-151.

Sloan, J. (2015). Experiments in Urban Luminosity. The Senses and Society, 10(2), 200-216. doi:10.108 $0 / 17458927.2015 .1042244$

Thomasson, S. (2015). Producing the Festival City: Place Myths and the Festivals of Adelaide and Edinburgh. (Geography PhD). Queen Mary University of London, London. Retrieved from https://qmro.qmul. ac.uk/xmlui/handle/123456789/9868

Tobelem, J.-M. (2017). La gestion des institutions culturelles musées, patrimoine, centres d'art (3e éd. revue et augmentée ed.). Malakoff: Armand Colin.

Wallach, J.-C. (2006). La culture, pour qui ? essai sur les limites de la démocratisation culturelle. Toulouse: Éd. de l'Attribut.

Recebido a 28/06/2019. Aceite para publicação a 05/09/2019

Manuel Garcia-Ruiz (manuel_ruiz@iscte-iul.pt | urbiteit@gmail.com). Instituto Universitário de Lisboa (ISCTEIUL), Escola de Sociologia e Políticas Públicas (ESPP), Centro de Investigação e Estudos de Sociologia do Instituto Universitário de Lisboa (CIES-IUL). Edifício Sedas Nunes, Av. das Forças Armadas, 1649-026 Lisboa, Portugal. 